\title{
EDUCAÇÃO A DISTÂNCIA NA PÓS-GRADUAÇÃO LATO SENSU EM GESTÃO DE SERVIÇOS E PRÁTICAS ASSISTENCIAS EM ENFERMAGEM: POSSIBILIDADES e LIMITAÇÕES.
}

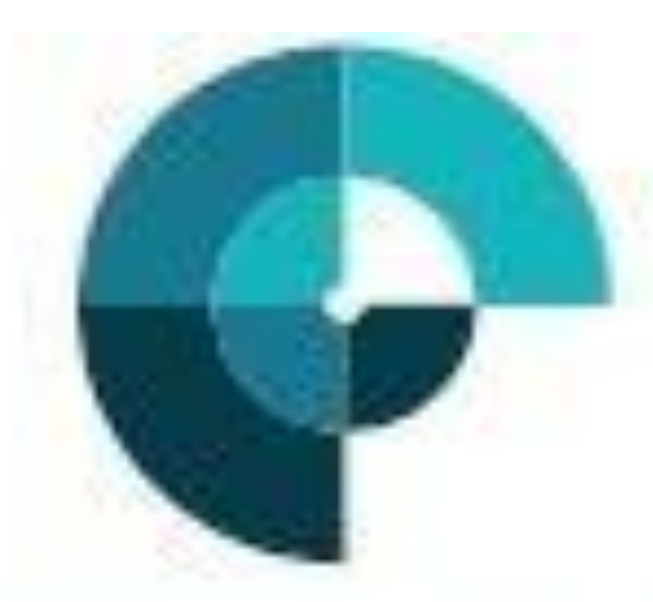

OSWALDO CRUZ

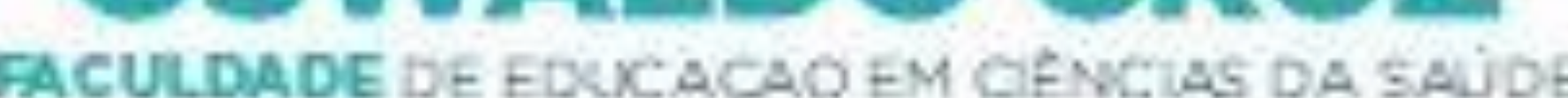

\author{
Maria Lúcia Alves Pereira Cardoso \\ Luciana Mendes Berlofi \\ Vitória Kachar \\ Daniela Aparecida Ramos Pimentel Damasceno Ferreira Motta
}

\section{INTRODUÇÃO}

As Instituições de Ensino Superior públicas e/ou privadas buscam implementar a Educação a Distância (EaD) para acompanhar a evolução das tecnologias de informação e comunicação, sendo que estas possibilitam a criação de novas abordagens de ensino e de aprendizagem, mediação pedagógica, novas formas de comunicação e de interatividade, ampliando a oferta de oportunidades de formação em nível superior ${ }^{1}$. No Brasil, ainda são tímidas as atividades relacionadas a essa modalidade educacional em áreas de saúde, portanto, iniciativas como as desse trabalho podem ser consideradas pioneiras e estão sujeitas a desafios e limitações.

\section{OBJETIVOS}

Apresentar o planejamento, desenvolvimento e implementação da educação à distância na Pós-graduação Lato Sensu em Gestão de Serviços e Práticas Assistenciais em Enfermagem da Faculdade de Educação em Ciências da Saúde - FECS, bem como as possibilidades e limitações.

\section{MÉTODO}

Trata-se do relato de experiência dessa disciplina híbrida, no qual apresenta um olhar analítico sobre o planejamento, desenvolvimento e a implementação desta e 0 que isso mobilizou de reflexão sobre a prática educativa, as formas de interação e acompanhamento dos alunos, assim como, os sentimentos, entusiasmo e a perseverança diante das limitações e desafios da docência e da coordenação na busca do sucesso dessa empreitada.

\section{RESULTADOS PRELIMINARES}

Planejamento, desenvolvimento e implementação:

Possibilidades e limitações

A disciplina de Metodologia da Pesquisa, do curso de Pósgraduação Lato Sensu em Gestão de Serviços e Práticas Assistenciais em Enfermagem foi implementada na modalidade híbrida, com $30 \%$ online. Foi desenvolvido um Ambiente Virtual de Aprendizagem - AVA com desenho instrucional que contempla: material de leitura, portfólio para entrega de produções do aluno, atividades com questões objetivas, gamificação e com comunicação contínua entre aluno e docente.
A análise de aproveitamento dos estudantes demonstrou que $100 \%$ aderiu às atividades online, evidenciadas pelas entregas de produtos propostos na disciplina. Observou-se uma baixa participação nos Fóruns e dificuldades na atividade de Gamificação (Desafio / Palavra Cruzada). A interação e acompanhamento dos estudantes, pela docente e coordenadora do curso, desencadearam atitudes de entusiasmo e perseverança diante das limitações e desafios na busca do sucesso dessa empreitada. E também, projetou a necessidade de viabilização de novos programas em EaD na Pós-graduação em Enfermagem.

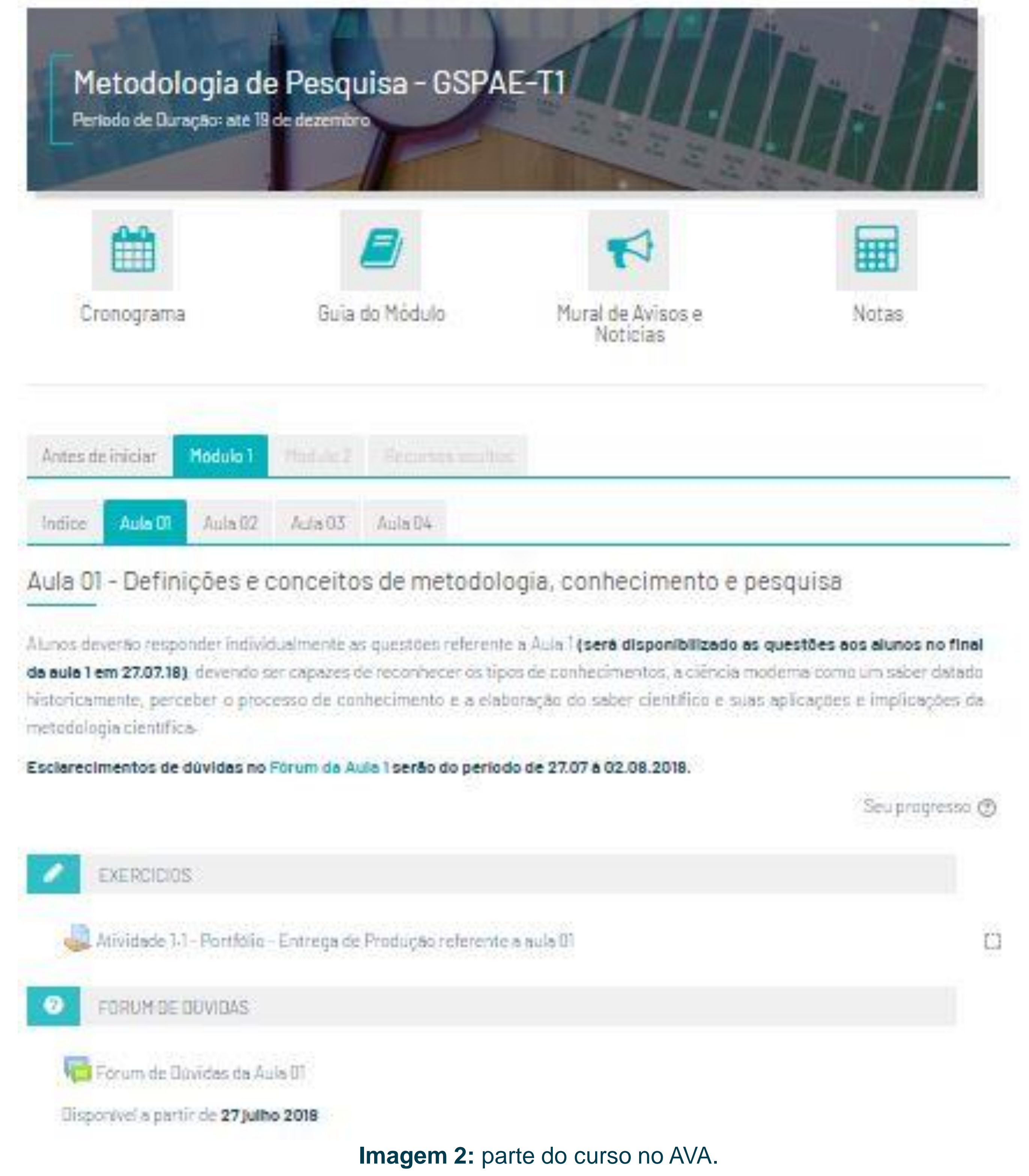

\section{CONSIDERAÇÕES FINAIS}

É preciso renovar as práticas docentes no processo de ensinoaprendizagem, acompanhando as novas linguagens de comunicação e interação, gerando uma nova perspectiva nas abordagens nos cursos de Pós-graduação na área de saúde.

\section{REFERÊNCIA}

1. Gabriela E. Possolli, Débora M. V. Makuch, Eliane R. F. Costa e Salete T. Arcanjo. Educação a distância na pós-graduação Lato Sensu na área da saúde: uma revisão integrativa. Interfaces da Educ., Paranaíba, v.6, n.16, p. 27-45, 2015. 